\title{
TRADUÇÃO AUDIOVISUAL ACESSÍVEL (TAVA): A SEGMENTAÇÃO LINGUÍSTICA NA LEGENDAGEM PARA SURDOS E ENSURDECIDOS (LSE) DA CAMPANHA POLÍTICA NA TELEVISÃO EM FORTALEZA
}

\author{
ACCESSIBLE AUDIOLINGUAL TRANSLATION (TAVA): \\ THE LINGUISTIC SEGMENTATION IN THE SUBTITLING FOR \\ THE DEAF AND HARD OF HEARING (SDH) OF THE POLITICAL
} CAMPAIGN ON TELEVISION IN FORTALEZA

\author{
Silvia Malena Modesto Monteiro* \\ Joao Francisco Dantas ${ }^{* \star}$
}

\section{RESUMO}

$\mathrm{O}$ presente artigo trata de uma pesquisa de cunho exploratório-experimental acerca da recepção de espectadores surdos e ouvintes à Legendagem para Surdos e Ensurdecidos (LSE) de campanhas políticas na televisão. A pesquisa teve como variáveis os parâmetros de legendagem: velocidade e segmentação. A referida pesquisa trabalhou com vídeos de campanhas políticas, que tinham legendas nas velocidades lenta (145 palavras por minuto) e rápida (180 palavras por minuto) e que apresentavam ou não problemas de segmentação linguística. A segmentação linguística consiste na divisão das falas em blocos semânticos, baseada nas unidades semânticas e sintáticas. Assim, os vídeos foram apresentados aos participantes da seguinte maneira: Legendas Lentas Bem Segmentadas (LBS), Lentas Mal Segmentadas (LMS), Rápidas Bem Segmentadas (RBS) e Rápidas Mal Segmentadas (RMS). 16 espectadores - oito ouvintes e oito surdos - participaram da pesquisa. Desta forma, foi realizado um experimento com um rastreador ocular, em que as medidas de número e duração de fixações oculares foram observadas (estudo experimental). Além disso, foram coletadas informações sobre as legendas por meio de relatos retrospectivos e questionários aplicados aos participantes (estudo exploratório). Os resultados dos estudos exploratório e experimental sugerem que problemas de segmentação podem causar desconforto na recepção das legendas, causando rupturas no processo de leitura, tanto para surdos como para ouvintes.

Palavras-chave: LSE, Segmentação, Rastreador Ocular.

\footnotetext{
* Universidade Estadual do Ceará, Fortaleza, CE. Brasil. malena.monteiro@uece.br ** Universidade Estadual do Ceará, Fortaleza, CE. Brasil. joaofld@hotmail.com
} 


\section{ABSTRACT}

The present article concerns the results of an exploratory-experimental research on the reception of deaf and hearing viewers to the Subtitling for the Deaf and Hard of hearing $(\mathrm{SDH})$ of political campaigns on television. The variables of the research are two parameters of subtitling: rate and segmentation. The research worked with videos of political campaigns which had subtitles in slow ( 145 words per minute) and fast ( 180 words per minute) rates and which presented or not linguistic segmentation problems. Linguistic segmentation consists of the division of speech in semantic blocks, based on semantic and syntactic units. Thus, the videos were presented to participants in the following way: slow well segmented subtitles, slow ill segmented subtitles, fast well segmented subtitles, fast ill segmented subtitles. 16 viewers - eight hearing and eight deaf participants were in the research. Thus, an experiment with an eye-tracker was developed. In this experiment, the number and the duration of eye fixations were observed (experimental study). Besides this, information about the subtitles was collected, by means of reports and questionnaires applied to the participants (exploratory study). The results of the two studies suggest that problems in the subtitle segmentation can cause discomfort during the reception of the subtitles, causing ruptures on the reading process, for both groups of deaf and hearing participants.

Keywords: SDH, Segmentation, Eye-tracker.

\section{INTRODUÇÃO}

A compreensão dos processos que envolvem a legendagem e sua recepção é um ponto importante para a melhoria desse instrumento para os espectadores, em geral, e para a comunidade surda, em particular. Melhorar a legenda significa melhorar a relação do surdo com o mundo em que está inserido, permitindo assim que ele melhor se aproprie das informações disponíveis no ambiente ao seu redor.

Buscando contribuir com a comunidade surda de modo a ampliar sua participação nas decisões de âmbito social, a pesquisa descrita no presente artigo, tratou da recepção de legendas em programas políticos veiculados na cidade de Fortaleza no ano de 2010. Buscou-se compreender de que forma a segmentação linguística (conceito que será explicado mais adiante) se tornou um possível elemento complicador na recepção das legendas, na perspectiva de surdos e ouvintes.

Podemos afirmar que esta pesquisa justifica-se social, acadêmica e institucionalmente. Socialmente, porque fomenta a discussão acerca da acessibilidade dos indivíduos aos meios audiovisuais existentes em nossa sociedade. Academicamente, justifica-se por ser um estudo que está inserido na linha de Tradução Audiovisual Acessível (TAVa), especificamente na área da legendagem, a qual cresce cada vez mais, nacional e internacionalmente. Na perspectiva institucional, justifica-se por buscar complementar o ciclo de pesquisas exploratórias 
voltadas para a recepção de legendas iniciado em 2003, na Universidade Estadual do Ceará, e que continua até os dias de hoje.

O estudo está alinhado a outros trabalhos que tratam da recepção de legendas (cf. D’YDEWALLE et al, 1987; PAVAKANUN, 1992; DE LINDE; KAY, 1999; DE BRUYCKER; D'YDEWALLE, 2003; ROMERO-FRESCO, 2010) e também a pesquisas desenvolvidas pelo grupo LEAD (Legendagem e Audiodescrição) (ARAÚJO; FRANCO, 2003; ARAÚJO, 2004; ARAÚJO, 2005; ARAÚJO, 2007; ARAÚJO, 2008; ARAÚJO, 2009; ARAÚJO; NASCIMENTO, 2011; ARAÚJO; VIEIRA; MONTEIRO, 2013) da Universidade Estadual do Ceará, principalmente o projeto CORSEL (A segmentação na legendagem para surdos e ensurdecidos - LSE: um estudo baseado em corpus,) e o ExLEG (Estudos Experimentais em Legendagem: análise da velocidade e da segmentação), ao qual esta pesquisa se vincula. A proposta trata da legendagem de programas políticos veiculados na televisão, assunto pouco explorado até então, além de ser uma das primeiras pesquisas com metodologia experimental, com a utilização do rastreador ocular, realizadas na UECE.

A pesquisa se norteou, principalmente, a partir dos parâmetros da velocidade (número de palavras ou de caracteres apresentadas por minuto na tela) e da segmentação (decisão de onde iniciar e terminar uma legenda), buscando investigar de formas exploratória e experimental a recepção de surdos e ouvintes no que diz respeito à legendagem de campanhas políticas na televisão brasileira. Buscamos verificar se as pressuposições nas pesquisas de recepção de legendas (ARAÚJO; FRANCO, 2003; ARAÚJO, 2004; ARAÚJO, 2005; ARAÚJO, 2007; ARAÚJO, 2008; ARAÚJO, 2009; ARAÚJO; NASCIMENTO, 2011; ARAÚJO; VIEIRA; MONTEIRO, 2013) sobre a influência da velocidade e da segmentação se confirmavam. Para isso, foram usados protocolos de pesquisa, tais como questionários e relatos retrospectivos, e também o rastreador ocular, para obtermos dados numéricos e informações acerca do processo de leitura das legendas.

O objetivo geral foi analisar a recepção de surdos e ouvintes da cidade de Fortaleza assistindo a programas políticos com legendas para surdos e ensurdecidos (LSE), para assim observar os parâmetros da segmentação e da velocidade. Especificamente, investigamos até que ponto legendas de campanhas políticas: a) lentas bem segmentadas podem facilitar a recepção de surdos e ouvintes; b) lentas mal segmentadas podem dificultar a recepção de surdos e ouvintes; c) rápidas bem segmentadas podem facilitar a recepção de surdos e ouvintes; d) rápidas mal segmentadas podem dificultar a recepção de surdos e ouvintes. 


\section{PERCURSO TEÓRICO}

\subsection{Legendagem e LSE}

Segundo Díaz Cintas e Remael (2007), as legendas podem ser classificadas, quanto ao seu critério linguístico, como intralinguísticas, interlinguísticas e bilíngues. As legendas intralinguísticas são aquelas cujo texto de partida (oral) e de chegada (escrito) estão na mesma língua. São normalmente utilizadas para o público surdo e ensurdecido (LSE), aprendizagem de línguas, karaokê, dialetos da mesma língua, notícias e anúncios. As legendas interlinguísticas são aquelas cujos textos de partida e de chegada estão em línguas diferentes. São geralmente mais conhecidas pelo público, entram e saem em blocos e são voltadas geralmente para ouvintes, podendo também ser utilizadas para surdos e ensurdecidos, quando a LSE for traduzida diretamente da língua estrangeira. Já as legendas bilíngues são aquelas veiculadas em duas línguas diferentes. Elas apresentam duas linhas, com cada linha trazendo a tradução em uma língua distinta. Nesta pesquisa, trabalhamos com a LSE intralinguística.

A Legendagem para Surdos e Ensurdecidos (LSE) ${ }^{1}$ é uma modalidade que faz parte da TAVa. Trata-se de uma modalidade que vem sendo cada vez mais explorada, dentro da área maior dos Estudos da Tradução e também muito utilizada nos produtos audiovisuais brasileiros. A LSE é voltada ao público surdo ou com algum grau de deficiência auditiva e vem ganhando cada vez mais importância e visibilidade em nossa sociedade pela questão da acessibilidade.

De forma simplificada, pode-se afirmar que a LSE consiste na tradução, em forma de texto escrito, das falas de uma produção audiovisual. Para Chaves (2012), ela é um recurso de acessibilidade e uma modalidade de tradução que

1. Tradução do termo "Subtitling for the Deaf and the Hard of Hearing" (SDH).

2. O termo "Estudos da Tradução" foi concebido por Holmes, no início da década de 1970, em seu conhecido ensaio The Name and the Nature of Translation Studies (O Nome e a Natureza dos Estudos da Tradução). Segundo o autor, o novo campo deveria descrever o fenômeno da tradução e o modo como ela se manifesta, além de estabelecer princípios gerais por meio dos quais esses fenômenos pudessem ser explicados e previstos. Toury (1995), Even-Zohar (2000), Williams e Chesterman (2002) são pesquisadores em tradução que se ocuparam em mapear a proposta de Holmes para desdobrá-la e incluir a relação da tradução com as tecnologias, bem como questões referentes à ética e profissionalização do tradutor. Conforme Williams e Chesterman (2002), os Estudos da Tradução poderiam dividir-se em doze diferentes áreas de pesquisa: 1) Tradução e análise textual 2) Avaliação e controle de qualidade da tradução; 3) Tradução de gêneros do discurso; 4) Tradução multimídia; 5) Tradução e tecnologia; 6) História da Tradução; 7) Tradução e Ética; 8) Terminologia e glossários; 9) Interpretação; 10) Processo tradutório; 11) Formação de tradutores; e 12) Tradução como profissão. Com a evolução dos Estudos da Tradução, a TAVa foi incluída ao seu escopo, com as modalidades de audiodescrição e legendagem para surdos e ensurdecidos (ADERALDO, 2014). 
difere da legendagem para ouvintes, pois possui informações adicionais relativas à identificação de falante e aos efeitos sonoros, as quais são traduzidas para viabilizar o acesso da comunidade surda à trilha sonora de um produto audiovisual.

A produção de uma legenda envolve aspectos técnicos e linguísticos. No Brasil, os aspectos técnicos de legendagem são pensados de maneiras diferentes para surdos e ouvintes. A legenda para ouvintes deve possuir no máximo duas linhas, apresentar um número de caracteres compatível com a velocidade de leitura do espectador, estar no centro da tela e ser exibida em blocos. Dependendo da velocidade da fala, a legenda deve ser editada a fim de permitir que o espectador a leia, olhe para as imagens e ouça o áudio, em um espaço de tempo calculado em segundos e milésimos de segundos (NAVES et al., 2016). As legendas para ouvintes, segundo Araújo (2009), são feitas com a ajuda de um software que permite a marcação, a tradução, a revisão e uma versão prévia da legenda. A autora acrescenta que a legibilidade da legenda é outro aspecto levado em consideração na legendagem feita para ouvintes, por isso a formatação é considerada importante.

No caso dos surdos e ensurdecidos, as legendas em geral não seguem esse padrão, principalmente as transmitidas pela televisão brasileira. Elas são exibidas em três ou mais linhas, com uma alta densidade lexical e com a tradução do áudio e a identificação do falante. Pesquisadores do grupo LEAD (ARAÚJO; FRANCO, 2003; ARAÚJO, 2004, 2005, 2007, 2008 e 2009; ARAÚJO; NASCIMENTO, 2011; CHAVES; ARAÚJO, 2014; ARAÚJO; ASSIS, 2014) defendem que a LSE seja elaborada de acordo com os parâmetros da legendagem para ouvintes, incluindo, além disso, a tradução dos efeitos sonoros e a identificação dos falantes. Na televisão brasileira, a LSE é feita pelo sistema norte-americano denominado closed caption $^{3}$, também conhecido pela sigla CC, transmitido via sinal de televisão. Esse tipo de legendagem é praticamente uma transcrição do que é dito, sem levar em conta padrões que possam tornar a legenda mais acessível a surdos e ensurdecidos. Essas legendas podem ser reproduzidas por um televisor que possua função para tal. Segundo Franco e Araújo (2011), closed caption é "um sistema de legendagem fechada ou oculta (o espectador precisa acessá-la no seu controle remoto do aparelho de TV ou DVD) em oposição à legendagem aberta" (p.7).

3. Nesse sistema, as legendas são convertidas em códigos eletrônicos e inseridas na linha 21 do intervalo vertical em branco do sinal da TV, ou seja, na barra horizontal localizada entre as imagens da televisão. O telespectador acessa a legenda por meio de um decodificador localizado no controle remoto do televisor. Essa legenda é produzida por um profissional chamado estenotipista (stenocaptioner), utilizando um estenótipo (stenotype), tipo de teclado ligado a um estenógrafo computadorizado (ARAÚJO, 2008, p. 62). 
Araújo e Franco (2003) mencionam a existência de dois tipos de LSE (closed caption) oferecidos pela televisão brasileira: roll up e pop on. A primeira é usada em programas ao vivo, como, por exemplo, em programas de entrevista e telejornais. As palavras são digitadas da esquerda para a direita e rolam continuamente de baixo para cima na parte inferior da tela da televisão. Já as legendas pop on aparecem e desaparecem em blocos, sendo utilizadas pelos canais de televisão em programas pré-gravados, como novelas, filmes e séries.

A legenda aberta, por sua vez, é aquela que já está disponível no programa, ou seja, não precisa ser acionada por meio do controle remoto. É usada, de forma geral, em campanhas políticas e institucionais. As LSEs que constituem o objeto desta pesquisa são do tipo aberta e pop on.

Segundo Naves et al. (2016), de forma geral, em todo o mundo, as empresas de legendagem adotam a mesma estratégia quanto ao número de linhas - máximo de duas linhas - que devem ter, no máximo, 37 caracteres cada. Essa medida é a utilizada na Europa, na regra dos seis segundos, comprovada em pesquisas experimentais de d'Ydewalle et al. (1987) como sendo o tempo máximo de permanência da legenda na tela. No Brasil, esse tempo é de 4 segundos. O sistema americano de closed caption utilizado no Brasil possibilita a exibição de uma legenda em mais de duas linhas, no caso da LSE. Porém, o grupo LEAD defende a ideia de d'Ydewalle et al. (1987), pois mais de duas linhas de legenda podem causar um esforço maior na leitura e prejudicar a harmonização de legendas e imagens durante a recepção.

Com base nos estudos de d'Ydewalle et al. (1987), Díaz Cintas e Remael (2007) estabeleceram três velocidades nas quais um espectador pode assistir de forma adequada a uma produção audiovisual: 145, 160 ou 180 palavras por minuto (ppm). Essas medidas foram transformadas por Díaz Cintas e Remael (2007) em caracteres por segundo, a fim de facilitar seu uso pelos legendistas. Os autores produziram tabelas que apresentam a velocidade em palavras por minuto e o tempo dividido em caracteres por segundo (cps), de acordo com os frames ou fotogramas do filme onde a legenda está localizada (DÍAZ CINTAS, REMAEL, 2007). 
Quadro 1. Caracteres por segundo (regra europeia)

\begin{tabular}{|c|c|c|c|c|c|}
\hline \multirow{7}{*}{$\begin{array}{l}145 \text { palavras por } \\
\text { minute }\end{array}$} & $\begin{array}{c}\text { Segundos: } \\
\text { Frames }\end{array}$ & Caracteres & $\begin{array}{c}\text { Segundos: } \\
\text { Frames }\end{array}$ & \multicolumn{2}{|c|}{ Caracteres } \\
\hline & 01:00 & 16 & 02:00 & \multicolumn{2}{|c|}{29} \\
\hline & 01:04 & 17 & 02:04 & \multicolumn{2}{|c|}{32} \\
\hline & 01:08 & 18 & 02:08 & \multicolumn{2}{|c|}{34} \\
\hline & $01: 12$ & 20 & $02: 12$ & \multicolumn{2}{|c|}{36} \\
\hline & $01: 16$ & 23 & $02: 16$ & \multicolumn{2}{|c|}{38} \\
\hline & 01:20 & 25 & $02: 20$ & \multicolumn{2}{|c|}{40} \\
\hline $\begin{array}{c}\text { Segundos: } \\
\text { Frames }\end{array}$ & Caracteres & $\begin{array}{c}\text { Segundos: } \\
\text { Frames }\end{array}$ & Caracteres & $\begin{array}{c}\text { Segundos: } \\
\text { Frames }\end{array}$ & $\begin{array}{c}\text { Carac- } \\
\text { teres }\end{array}$ \\
\hline 03:00 & 44 & 04:00 & 58 & 05:00 & 71 \\
\hline 03:04 & 46 & 04:04 & 60 & 05:04 & 71 \\
\hline 03:08 & 48 & 04:08 & 62 & 05:08 & 73 \\
\hline $03: 12$ & 50 & $04: 12$ & 64 & $05: 12$ & 73 \\
\hline $03: 16$ & 52 & $04: 16$ & 65 & $05: 16$ & 74 \\
\hline 03:20 & 54 & $04: 20$ & 67 & $05: 20$ & 74 \\
\hline \multirow{7}{*}{160 palavras } & $\begin{array}{c}\text { Segundos: } \\
\text { Frames }\end{array}$ & Caracteres & $\begin{array}{c}\text { Segundos: } \\
\text { Frames }\end{array}$ & \multicolumn{2}{|c|}{ Caracteres } \\
\hline & 01:00 & 17 & 02:00 & \multicolumn{2}{|c|}{31} \\
\hline & 01:04 & 18 & 02:04 & \multicolumn{2}{|c|}{34} \\
\hline & 01:08 & 20 & 02:08 & \multicolumn{2}{|c|}{37} \\
\hline & $01: 12$ & 23 & $02: 12$ & \multicolumn{2}{|c|}{40} \\
\hline & $01: 16$ & 26 & $02: 16$ & \multicolumn{2}{|c|}{42} \\
\hline & 01:20 & 28 & $02: 20$ & \multicolumn{2}{|c|}{44} \\
\hline $\begin{array}{c}\text { Segundos: } \\
\text { Frames }\end{array}$ & Caracteres & $\begin{array}{c}\text { Segundos: } \\
\text { Frames }\end{array}$ & Caracteres & $\begin{array}{c}\text { Segundos } \\
\text { Frames }\end{array}$ & $\begin{array}{c}\text { Carac- } \\
\text { teres }\end{array}$ \\
\hline 03:00 & 48 & 04:00 & 63 & 05:00 & 75 \\
\hline 03:04 & 50 & 04:04 & 65 & 05:04 & 75 \\
\hline 03:08 & 53 & 04:08 & 67 & 05:08 & 76 \\
\hline $03: 12$ & 56 & $04: 12$ & 69 & $05: 12$ & 76 \\
\hline $03: 16$ & 58 & $04: 16$ & 71 & $05: 16$ & 77 \\
\hline $03: 20$ & 60 & $04: 20$ & 73 & $05: 20$ & 77 \\
\hline & & & & 06:00 & 78 \\
\hline
\end{tabular}




\begin{tabular}{|c|c|c|c|c|c|}
\hline \multirow{7}{*}{180 palavras } & $\begin{array}{c}\text { Segundos: } \\
\text { Frames }\end{array}$ & Caracteres & $\begin{array}{c}\text { Segundos: } \\
\text { Frames }\end{array}$ & \multicolumn{2}{|c|}{ Caracteres } \\
\hline & 01:00 & 17 & 02:00 & \multicolumn{2}{|c|}{35} \\
\hline & 01:04 & 20 & 02:04 & \multicolumn{2}{|c|}{37} \\
\hline & 01:08 & 23 & 02:08 & \multicolumn{2}{|c|}{39} \\
\hline & $01: 12$ & 26 & $02: 12$ & \multicolumn{2}{|c|}{43} \\
\hline & 01:16 & 28 & $02: 16$ & \multicolumn{2}{|c|}{45} \\
\hline & $01: 20$ & 30 & $02: 20$ & \multicolumn{2}{|c|}{49} \\
\hline $\begin{array}{c}\text { Segundos: } \\
\text { Frames }\end{array}$ & Caracteres & $\begin{array}{c}\text { Segundos: } \\
\text { Frames }\end{array}$ & Caracteres & $\begin{array}{c}\text { Segundos } \\
\text { Frames }\end{array}$ & $\begin{array}{c}\text { Carac- } \\
\text { teres }\end{array}$ \\
\hline 03:00 & 53 & 04:00 & 70 & 05:00 & 78 \\
\hline 03:04 & 55 & 04:04 & 73 & 05:04 & 78 \\
\hline 03:08 & 57 & 04:08 & 76 & 05:08 & 78 \\
\hline $03: 12$ & 62 & $04: 12$ & 76 & $05: 12$ & 78 \\
\hline $03: 16$ & 65 & $04: 16$ & 77 & $05: 16$ & 78 \\
\hline $03: 20$ & 68 & $04: 20$ & 77 & 05:20 & 78 \\
\hline & & & & 06:00 & 78 \\
\hline
\end{tabular}

Fonte: Díaz Cintas e Remael (2007, p. 97-99).

No caso, o legendista observa a duração da fala e faz a legenda de acordo com o número de caracteres correspondente no quadro. Por exemplo, se temos uma fala com duração de um segundo e 20 frames (01:20), ela pode ter até 25, 28 ou 30 caracteres, se a velocidade for de 145, 160 ou $180 \mathrm{ppm}$, respectivamente.

O grupo LEAD - UECE vem observando em suas pesquisas a influência de parâmetros de legendagem, tais como a velocidade da legenda e a segmentação, na recepção das legendas pelo público surdo. Conforme já mencionado, velocidade diz respeito ao número de palavras (ou de caracteres) apresentadas por minuto na tela e a segmentação diz respeito à divisão das falas em blocos semânticos, baseada nas unidades semânticas e sintáticas. Segundo Chaves (2012), a segmentação consiste na subdivisão das legendas. Ou seja, é a decisão de onde iniciar e terminar uma legenda. Para a autora, uma boa segmentação deve respeitar o corte ou mudança de cena, o fluxo da fala e a sintaxe, além de conter um pensamento completo, a fim de facilitar a leitura.

Pesquisas iniciais (ARAÚJO, 2004, 2005, 2007, 2008) apontavam para o parâmetro da velocidade como sendo o principal responsável pela má recepção das legendas pelos surdos. Dessa forma, os pesquisadores à época concluíram que as velocidades acima de 145 palavras por minuto (ppm) e a ausência de redução 
textual das legendas seriam os principais entraves a uma boa compreensão das legendas. No entanto, uma pesquisa exploratória (Projeto MOLES - Modelo de Legendagem para Surdos) (ARAÚJO; NASCIMENTO, 2011; ARAÚJO; VIEIRA; MONTEIRO, 2013) desenvolvida em quatro regiões brasileiras com 34 participantes surdos gerou a hipótese de que a segmentação, e não a velocidade, seria o principal parâmetro que influencia a recepção das legendas, em virtude de que os participantes da referida pesquisa apresentaram uma boa recepção, inclusive das legendas rápidas (180ppm). Os resultados do Projeto MOLES deram uma nova perspectiva aos estudos do LEAD, que agora direciona sua atenção para o parâmetro da segmentação.

Reid (1990) apresenta três critérios de uma segmentação adequada: Linguístico: pautado pela sintaxe, ou seja, cada linha de legenda deve conter um pensamento (o mais completo possível), Retórico: pautado pelo fluxo da fala, ou seja, após uma pausa, uma nova legenda deve ser produzida; Visual: pautado pelo corte de cena, ou seja, sempre que a mudança de cena coincidir com o tempo de saída de uma legenda, esta não deve durar até a cena seguinte. $\mathrm{O}$ foco da pesquisa que aqui descrevemos foi a segmentação linguística.

Segundo Díaz Cintas e Remael (2007), a segmentação linguística pode ocorrer entre duas legendas diferentes ou dentro da mesma legenda (chamada de quebra de linha). Atualmente, ela tem sido bastante discutida nos estudos da TAVa, suscitando cada vez mais pesquisas quanto à sua importância na legendagem (IVARSSON; CARROLL, 1998; KARAMITROGLOU, 1998; PEREGO, 2008; CHAVES, 2012; ARAÚJO; CHAVES, 2012).

Para Karamitroglou (1998), o texto deve ser segmentado no mais alto nível sintático possível, fazendo com que cada legenda possua um sentido completo. $\mathrm{O}$ autor afirma que, ao segmentarmos uma legenda, forçamos o cérebro a pausar seu processamento linguístico e, por isso, essa pausa deve ser feita quando a carga semântica puder oferecer uma informação completa. Para Díaz Cintas e Remael (2007), quando a segmentação não ocorre dessa forma, o espectador pode ter problemas de recepção, se cansando rapidamente e perdendo o interesse em assistir a um filme, por exemplo, devido ao esforço despendido.

Pesquisadores como Diniz (2012), Chaves (2012) e Assis (2013) desenvolveram pesquisas descritivas sobre a segmentação linguística. Todas essas pesquisas usaram LSE de produtos audiovisuais acessíveis (filmes e novela), estudando a quebra indevida entre linhas de legendas. Os resultados das três pesquisas apontaram para o sintagma verbal como sendo a quebra indevida de maior ocorrência nas legendas. 
A partir dos resultados das referidas pesquisas, o grupo LEAD desenvolveu, no ano de 2015, um novo projeto de estudo descritivo chamado CORSEL, mencionado anteriormente. O projeto trata dos problemas de segmentação linguística encontrados na LSE de programas audiovisuais nos gêneros: novelas, seriados do tipo comédias de situação e documentários exibidos por emissoras brasileiras em programas pré-gravados. O estudo foi desenvolvido utilizando como abordagem metodológica a Linguística de Corpus e teve o objetivo de localizar e compreender o universo dos problemas de segmentação linguística que ocorrem na LSE nos gêneros mencionados. Os pesquisadores desse projeto desenvolveram etiquetas, as quais denominaram "etiquetas de segmentação", a fim de classificar os problemas de segmentação linguística das legendas nos níveis dos sintagmas e das orações. A partir da classificação dos sintagmas sob um viés funcionalista (CASTILHO, 2012) apresentada pelos pesquisadores do CORSEL, a pesquisa aqui descrita utilizou as etiquetas para criar os problemas de segmentação linguística entre legendas, no gênero campanha política, objetivando testar a recepção dessas legendas experimentalmente, por meio do rastreamento ocular de surdos e ouvintes.

As pesquisas em LSE tornam-se cada vez mais frequentes no Brasil e no mundo. Nesse contexto, ressaltamos a importância da introdução de pesquisas experimentais para discutir o tema, principalmente aquelas que utilizam o rastreador ocular. Por meio desse aparelho, é possível obter resultados mais claros, que podem fomentar os estudos relativos à área da TAVa e, mais especificamente, da LSE, e assim contribuir com o estado da arte.

\section{RASTREAMENTO OCULAR}

Segundo Reichle et al. (2003), a leitura é uma tarefa complexa que envolve muitos estágios de processamento da informação e na qual a compreensão é essencial em muitos níveis. Nesse sentido, as informações relativas ao movimento ocular são muito importantes quanto se trata de compreender a leitura.

Para Staub e Rayner (2007), informações sobre onde o leitor fixa o olhar no texto e por quanto tempo ele olha para determinada parte do texto enquanto lê podem fornecer dados confiáveis sobre a compreensão em vários níveis. Os olhos, ao se movimentarem, realizam "saltos", chamados de sacadas, e, entre essas sacadas, eles permanecem relativamente estáveis - fixações. As sacadas geralmente levam de 20 a 40 milissegundos, e as fixações permanecem em uma média de 200 a 250 milissegundos, sendo o mínimo entre 50 e 100 milissegundos e o máximo em torno de 500 milissegundos. Durante as sacadas, a retina capta a informação, mas 
o sistema visual não a registra. É, portanto, na fixação que a informação relevante é extraída (STAUB; RAYNER, 2007; RAYNER et al., 2013). De acordo com Reichle et al. (2003), em textos impressos, as pesquisas revelaram que a decisão de fazer uma sacada é muitas vezes feita dentro dos primeiros $100 \mathrm{~ms}$ de fixação e que o acesso lexical dura em torno de 100-300ms.

No que diz respeito à fisiologia da visão, se observarmos o texto que está compreendido em uma fixação, podemos dividi-lo em três regiões: a foveal - o texto dentro de aproximadamente 1 grau do ângulo de visão de cada lado do ponto de fixação, três ou quatro palavras à esquerda e à direita da fixação; a parafoveal, em que a acuidade visual cai, mas o leitor ainda consegue identificar algumas letras - vai até cinco graus do ângulo visual dos dois lados do ponto de fixação; e a visão periférica, em que o leitor sabe, por exemplo, o formato do texto. Assim, o leitor de fato identifica palavras numa extensão de 7 ou 8 caracteres à direita da fixação, o que pode variar de acordo com a dificuldade do texto (STAUB; RAYNER, 2007).

Reichle et al. (2003) afirmam que existem evidências de que quanto maior for a disparidade angular entre a fóvea e a imagem da retina, mais difícil é para o leitor identificar a palavra. Segundo eles, a parafóvea pode causar o efeito de "pular" as palavras, já que aquelas que ela identifica não precisam ser fixadas, por isso o leitor "salta" essas palavras. Os autores mencionam que pesquisas com rastreamento ocular vêm demonstrando que antes da fixação da palavra vem o seu processamento ortográfico e fonológico. Assim, durante a leitura, quando a parafóvea prevê uma palavra, a duração da fixação na próxima palavra é reduzida.

Já existem evidências de que a dificuldade de processamento de uma palavra influencia o movimento do olhar. Ou seja, as propriedades linguísticas e lexicais da palavra influenciam o tempo de fixação do olhar naquela palavra, o que reflete o seu tempo de processamento (RAYNER; POLLATSEK,1989; REICHLE et al., 2003; STAUB; RAYNER, 2007; RAYNER et al., 2012). É interessante perceber que no processo de leitura, as palavras de conteúdo, como os substantivos, tendem a ser mais fixadas, enquanto as palavras de função, como as preposições, que em geral são curtas, tendem a ser mais "saltadas" (ignoradas) (CARPENTER; JUST, 1983; RAYNER et al., 2013). Assim, pode-se afirmar que o leitor tende a "pular" as palavras curtas com maior frequência, talvez por ser mais provável identificá-las quando a palavra anterior está sendo fixada. Szarkowska et al. (2013) resumem esse pensamento, afirmando que a duração de uma fixação depende de muitos fatores, tais como: tamanho da palavra - as palavras longas têm mais probabilidade de ser fixadas do que as curtas; frequência - quanto mais frequente a palavra, menos fixada ela tende a ser; e categoria gramatical da palavra - palavras de conteúdo são mais 
fixadas do que palavras de função. De fato, pesquisas (O'REGAN, 1979; RAYNER et al., 1996; RAYNER, 1998; RAYNER et al., 2013) mostraram que as palavras frequentes são mais "saltadas", enquanto o tempo de leitura na palavra subsequente aumenta. Por outro lado, o tempo dedicado a palavras de baixa frequência diminui bastante quando elas se repetem no texto. Szarkowska et al. (2013) afirmam ainda que ler legendas é um processo mais complexo do que ler textos monossemióticos, já que quem lê a legenda tem que também olhar a imagem.

Staub e Rayner (2007), assim como Szarkowska et al. (2013), afirmam que o tamanho da palavra, a sua frequência e a sua previsibilidade podem ser indicativos do tempo que os olhos se fixam nela. No entanto, afirmam os autores, existem outros fatores linguísticos que podem influenciar essas fixações, tais como o processamento sintático da sentença e o processamento do discurso.

Como podemos observar, são muitos os fatores que influenciam a fixação das palavras na leitura. Ao realizarmos pesquisa com rastreamento ocular, esses fatores devem ser cuidadosamente observados, para que não façamos generalizações errôneas ou tiremos conclusões precipitadas sobre o comportamento ocular estudado. Por isso, esta pesquisa se propôs a observar esses aspectos inerentes à leitura, em conjunto com os dados numéricos fornecidos pelo rastreador ocular. Trata-se de uma pesquisa contínua, que não se encerra aqui, mas que busca trazer mais indícios sobre como se dá todo esse processo e o que pode estar por trás das dificuldades do espectador de legendas. Cada vez mais crescem em número as pesquisas com rastreamento ocular, por isso esta é uma discussão contínua e cheia de descobertas a cada experimento realizado.

\section{PESQUISAS COM RASTREAMENTO OCULAR}

Autores como De Linde e Kay (1999), Perego et al. (2010) e Romero-Fresco (2010) realizaram pesquisas triangulando dados numéricos (rastreador ocular) e dados exploratórios (relatos e questionários). Para De Linde e Kay (op. cit.), a leitura é um processo complexo e apenas parte dele pode ser revelado pela análise do movimento ocular. Por isso, afirmam os autores, os questionários são importantes. De Linde e Kay (1999) trabalharam com um grupo de surdos e outro de ouvintes, como ocorreu nesta pesquisa. Como material de análise, os autores utilizaram vídeos extraídos de programas de canais britânicos. Já Romero-Fresco (2010) trabalhou com ouvintes, comparando legendas roll up e pop on, enquanto Perego et al. (2010) trabalharam com ouvintes assistindo a trechos de filmes, que misturavam legendas bem e mal segmentadas. Todos esses autores utilizaram medidas como número e 
duração das fixações, e suas metodologias contribuíram na estruturação da pesquisa aqui descrita.

Perego et al. (2010) observaram como se dá o processamento da informação presente nas legendas bem e mal segmentadas de trechos de filmes. Mesmo apresentando resultados diferentes dos desta pesquisa (em sua pesquisa, legendas bem e mal segmentadas tiveram boa recepção), pois utilizamos metodologias diferentes em vários pontos, seus resultados nos forneceram informações importantes no que diz respeito ao movimento ocular e à atenção direcionada para imagem e legenda. Assim como ocorreu com pesquisadores como d'Ydewalle e De Bruycker (2007), Perego et al. observaram que os espectadores de vídeos legendados tendem a fazer um número maior de fixações nas legendas, devido ao processo de leitura, porém fixações mais longas na imagem, já que as fixações na leitura de legendas são geralmente mais curtas. Eles explicam que uma análise mais detalhada dessas fixações mostrou que as fixações mais curtas nas legendas se estendiam por todo o texto escrito, enquanto as fixações mais longas na área visual tendiam a focar em partes específicas, visualmente salientes e que capturavam a atenção" (p. 263 , tradução nossa) ${ }^{4}$. Os autores mencionam terem obtido em seus resultados bons níveis de reconhecimento e de compreensão das legendas pelos participantes. Assim, a partir das descobertas de d'Ydewalle e De Bruycker (2007) e de Perego et al. (2010), esta pesquisa sugere que a presença de fixações mais longas na imagem do que na legenda pode ser um ritmo comum, ou até confortável, de leitura de legendas. Romero-Fresco (2010) também mostra em seus resultados que quanto maior o tempo de fixações na imagem, melhor pode ser o ritmo de leitura, pois se o espectador gasta menos tempo na legenda, sobra mais tempo para que ele possa ver também a imagem. Ele percebeu isso ao comparar legendas refaladas do tipo roll up e pop on, observando ao final do experimento que as pop on apresentaram melhores resultados quanto ao desempenho dos participantes. Em nossos dados, observamos que, na maioria das vezes, a duração mais longa das fixações na legenda ocorria quando havia um elemento explícito que poderia gerar desconforto e problemas na recepção, principalmente a má segmentação das legendas. Quanto ao número de fixações, Romero-Fresco também obteve os mesmos dados de d'Ydewalle e De Bruycker (2007) e Perego et al. (2010) - um número maior de fixações na legenda do que na imagem.

4. [...] shorter fixations on subtitles spanned over the whole written text, while longer fixations on the visual area tended to focus on specific, visually salient and attention-capturing parts of the scene (PEREGO et al., 2010, p. 263). 


\section{METODOLOGIA}

A pesquisa foi realizada no Laboratório Experimental de Rastreamento Ocular (LERO) da Universidade Estadual do Ceará, tendo caráter descritivo e exploratório, com procedimentos experimentais, e abordagem quanti-qualitativa. Além disso, faz parte de um projeto maior - Estudos Experimentais em Legendagem: análise da velocidade e da segmentação (ExLEG) -, cujo objetivo é analisar experimentalmente os parâmetros de legendagem relacionados à velocidade e à segmentação.

O corpus consistiu de um conjunto de legendas intralinguísticas abertas do tipo pop on exibidas em programas políticos, veiculados na televisão da cidade de Fortaleza durante o período das eleições. As legendas foram selecionadas a partir de 4 vídeos (menos de 2 minutos de duração, cada).

Essas legendas foram, então, manipuladas de forma a se encaixarem nas condições experimentais que queríamos testar: legenda lenta bem segmentada (LBS), legenda lenta mal segmentada (LMS), legenda rápida bem segmentada (RBS) e legenda rápida mal segmentada (RMS). Ou seja, cada vídeo passou a ter quatro tipos de legenda.

Ao todo, participaram da pesquisa 16 pessoas, divididas em dois grupos: um grupo controle composto por oito ouvintes; e um grupo experimental composto por oito surdos. $\mathrm{O}$ grupo controle era composto por: três homens e cinco mulheres, de 18 a 42 anos. Dos oito, três com nível superior completo e cinco com nível superior incompleto; dois apresentavam problemas de visão; dois afirmaram ver programas legendados todos os dias. Os outros afirmaram ver: três vezes na semana (dois), duas vezes (um), raramente (três); dos oito, sete afirmaram ter costume de ir ao cinema, da mesma forma que sete afirmaram alugar ou assistir a filmes legendados no computador. Com relação à frequência com que assistem a programas políticos, os participantes ficaram distribuídos da seguinte maneira: todo dia (nenhum), três vezes por semana (um), duas vezes por semana (três), raramente (um) e não assistem (três).

Já o grupo experimental era composto por seis homens e duas mulheres, de 18 a 42 anos. Dos oito, cinco possuíam nível superior completo e três, incompleto; apenas três afirmaram ter problemas de visão; cinco afirmaram ter nascido surdos e três disseram que ficaram surdos antes dos cinco anos de idade; seis afirmaram ter surdez profunda e dois, moderada; todos afirmaram ser alfabetizados em Libras, tendo aprendido a língua: na escola (quatro), em associações (dois), com um vizinho (um), e na igreja (um); dos oito, quatro afirmaram ver programas legendados todos os dias, um 3 vezes na semana, um 2 vezes e dois raramente; sete disseram ir com frequência ao cinema; Todos afirmaram alugar ou assistir a filmes legendados no 
computador. Com relação à frequência com que assistem a programas políticos, os participantes ficaram distribuídos da seguinte maneira: todo dia (nenhum), 3 vezes por semana (um), 2 vezes por semana (três), raramente (um) e não assistem (três).

Como instrumentos de coleta de dados, foram utilizados protocolos verbais (relato retrospectivo livre; questionário pós-coleta; relato retrospectivo guiado estudo exploratório) e o rastreamento ocular - estudo experimental. O modelo do rastreador ocular utilizado nesta pesquisa foi o Tobii TХзоо Eye Tracker, que funciona em conjunto com o software Tobii Studio versão 3.2. É composto por uma tela de 23 polegadas com resolução máxima de 1920 x 1080 pixels, com brilho de tela de $300 \mathrm{~cd} / \mathrm{m}^{2}$ (candela por metro quadrado - medida usada pelos fabricantes de imagem para transmissão de produtos audiovisuais) - suficiente para produzir uma imagem de excelente qualidade, além de alto-falantes embutidos e uma câmera frontal inserida na parte superior da tela capaz de produzir vídeos com tamanho de resolução 640 x 480 com 30fps (frame rate - frames por segundo), que permite que o participante seja gravado durante o experimento.

Os procedimentos consistiram em duas fases: 1) análise e manipulação das legendas; 2) desenvolvimento do experimento, em que observamos a influência da segmentação nas legendas apresentadas a surdos e ouvintes.

Na primeira fase foi realizada a edição dos vídeos (vídeos com um minuto de duração, em média), a relegendagem dos vídeos, colocando-os nas quatro condições analisadas na pesquisa (legendas lentas $-145 \mathrm{ppm}$ - bem e mal segmentadas e legendas rápidas - 180ppm - bem e mal segmentadas) e a etiquetagem das legendas, identificando os problemas de segmentação nelas presentes.

$\mathrm{Na}$ segunda fase da pesquisa foi desenvolvido o experimento no rastreador ocular. Com o intuito de organizar a sequência dos vídeos e dos participantes, utilizamos um desenho experimental baseado no conceito de quadrado latino, proposto por Marquer (2003): cada participante é exposto a todas as condições experimentais e as unidades experimentais que recebem os tratamentos são agrupadas de formas diferentes (linhas e colunas). O número de linhas e colunas deve ser o mesmo e os tratamentos devem ser distribuídos de maneira que cada participante só seja submetido uma única vez a cada uma das quatro condições experimentais (LBS, LMS, RBS, RMS). Assim, todos os 16 participantes (oito ouvintes e oito surdos) assistiram aos quatro vídeos, nas quatro condições. Cada participante foi exposto a quatro condições experimentais, sendo que cada condição era exibida em um vídeo diferente. No quadro a seguir, demonstramos como foi organizada a distribuição dos vídeos, de acordo com o desenho estabelecido. 
Quadro 2. Organização dos participantes e distribuição dos vídeos

\begin{tabular}{|c|c|c|c|c|}
\hline Participantes & Vídeo/ & Vídeo/ & Vídeo/ & Vídeo/ \\
(O: Ouvintes & Condição & Condição & Condição & Condição \\
\hline S: Surdos) & & & & \\
\hline O1/O5/S1/S5 & $1 / \mathrm{LBS}$ & $2 / \mathrm{LMS}$ & $3 / \mathrm{RBS}$ & $4 / \mathrm{RMS}$ \\
\hline $\mathrm{O} 3 / \mathrm{O} 6 / \mathrm{S} 2 / \mathrm{S} 63 / \mathrm{S} 7$ & $1 / \mathrm{LMS}$ & $2 / \mathrm{RBS}$ & $3 / \mathrm{RMS}$ & $4 / \mathrm{LBS}$ \\
\hline $\mathrm{O} 4 / \mathrm{O} 8 / \mathrm{S} 4 / \mathrm{S} 8$ & $1 / \mathrm{RBS}$ & $2 / \mathrm{RMS}$ & $3 / \mathrm{LBS}$ & $4 / \mathrm{LMS}$ \\
\hline
\end{tabular}

Fonte: Autores.

As variáveis independentes da pesquisa foram a segmentação e a velocidade, e foram testadas com o intuito de observarmos sua possível interferência na recepção das legendas pelos participantes. As variáveis dependentes, por sua vez, foram as medidas observadas durante o experimento (número e duração das fixações). A fixação consiste no tempo em que o espectador fixa o olhar em um determinado ponto. Já a duração da fixação é a quantidade de tempo que uma determinada fixação pode durar. Pelos dados numéricos fornecidos pelo rastreador pudemos obter esses números, tanto para surdos quanto para ouvintes.

A coleta de dados foi realizada com cada um dos 16 participantes na seguinte sequência: assinatura do Termo de Consentimento Livre e Esclarecido; preenchimento do questionário de perfil do participante; calibragem do olhar no rastreador ocular, para início do experimento; apresentação de cada vídeo, seguida do relato livre do participante e da aplicação do questionário pós-coleta, sobre as impressões do participante acerca das legendas. Finalmente, cada participante era exposto à gravação do movimento ocular durante a exibição dos vídeos, e convidado a responder algumas perguntas e a fazer colocações sobre o caminho do olhar no rastreador, a fim de compreender melhor seu processo de leitura. Assim, a análise foi realizada por meio da triangulação dos dados provenientes dos protocolos de pesquisa (estudo exploratório) e dos dados numéricos fornecidos pelo rastreador ocular (estudo experimental).

\section{ANÁLISE E RESULTADOS}

A análise, conforme já mencionado, foi exploratória-experimental. Na análise exploratória, partimos do princípio de que quanto mais detalhados fossem os relatos dos participantes e quanto melhor eles conseguissem harmonizar imagem e legenda, 
mais confortável teria sido a recepção das legendas. Já na análise experimental (numérica, baseada nos dados do rastreador ocular - número e duração das fixações), partimos do princípio de que quanto mais tempo o participante conseguisse fixar as imagens, mais confortável teria sido a recepção, pois não teria ficado muito tempo fixando as legendas, buscando entendê-las.

\section{ANÁLISE EXPLORATÓRIA}

Durante o experimento no rastreador, após a exibição de cada vídeo, os participantes realizaram o relato livre, e depois responderam às perguntas do questionário pós-coleta sobre a sua opinião acerca das legendas. Após todos os vídeos terem sido exibidos, os participantes foram convidados a realizar um relato guiado, observando e comentando o seu comportamento ocular e relembrando o seu processo de leitura das legendas. Tudo com o objetivo de analisar a recepção de cada participante (surdo e ouvinte) a cada vídeo apresentando, observando se ele compreendeu o conteúdo e os detalhes do vídeo e se apresentou uma boa recepção das legendas. A figura a seguir representa a tela da gravação do olhar:

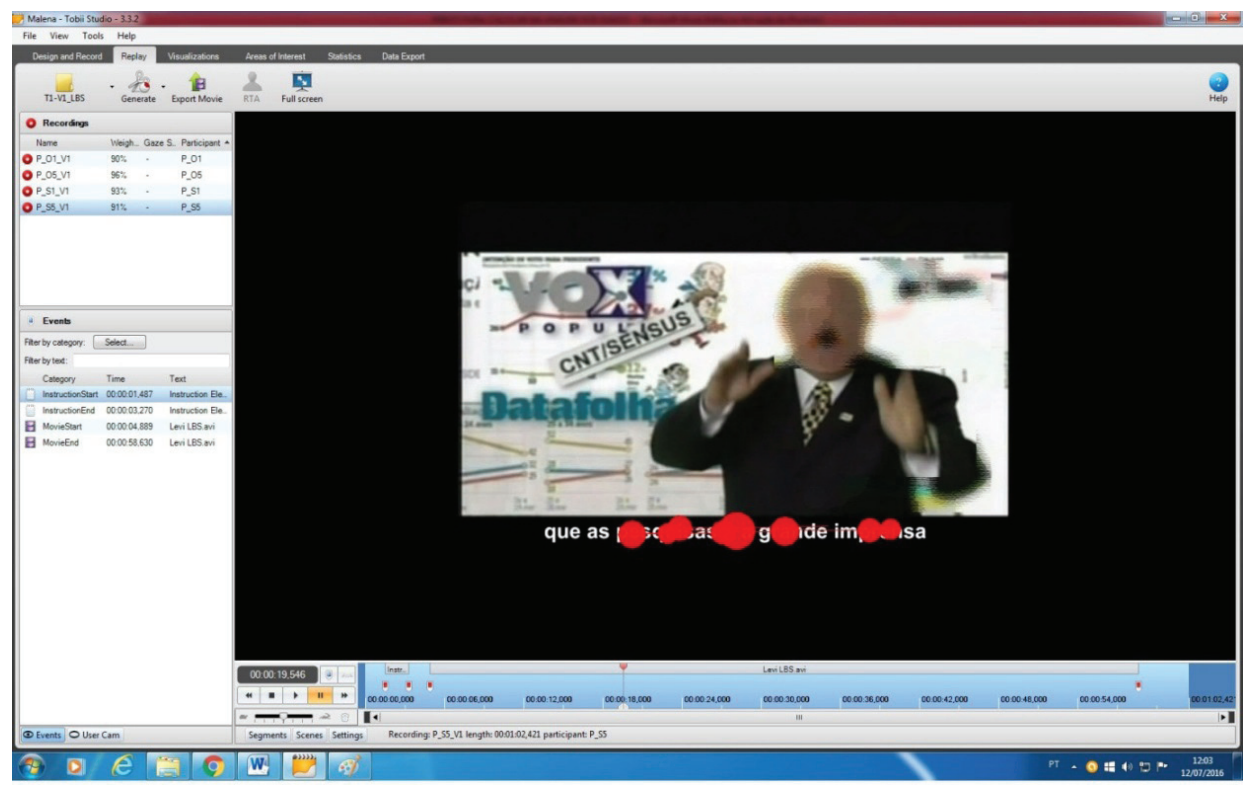

Figura 1. Exemplo da gravação do olhar de um participante 
Apresentamos a seguir os resultados obtidos por meio dos referidos protocolos, organizados por condição experimental nesta sequência: LBS, LMS, RBS e RMS.

Podemos afirmar que, nas legendas LBS, todos os participantes (surdos e ouvintes) identificaram o conteúdo do vídeo, tendo um número maior de surdos do que de ouvintes apresentado detalhes. Os surdos mostraram, em seus relatos guiados, terem fixado mais nas legendas do que nas imagens. $\mathrm{O}$ número de surdos e ouvintes que fizeram fixações longas na legenda foi equilibrado, praticamente a mesma quantidade.

Dentre os oito surdos, três afirmaram não ter conseguido acompanhar imagem e legenda sem fazer esforço. Para eles, as explicações para esse fato foram as seguintes: medo de sair da legenda e perder conteúdo; imagens estáticas que os faziam querer ficar na legenda. Quanto aos ouvintes, todos afirmaram ter conseguido acompanhar imagem e legenda sem esforço. Os dados desses participantes sugerem que as legendas estavam lentas, pois relataram que sentiram que ficaram esperando, sem olhar para a imagem, a próxima legenda.

Em relação à velocidade, dentre os 16 participantes, cinco consideraram que as legendas estavam rápidas e 11 as consideraram que estavam numa velocidade normal. Não surgiram reclamações no que diz respeito ao conteúdo das legendas, somente em relação à presença de palavras desconhecidas, no caso dos participantes surdos. É interessante observar que as palavras desconhecidas são assunto recorrente no discurso dos surdos; eles consideram que elas dificultam a leitura. De fato, textos que são mais difíceis levam a fixações mais longas e a sacadas mais curtas (RAYNER; POLLATSEK, 1989; RAYNER et al., 2012). Além disso, existe a questão da frequência das palavras, já mencionada no início deste capítulo. Reichle et al. (2003) corroboram essa ideia quando afirmam que a dificuldade ou a facilidade de processar uma palavra tem influência decisiva no movimento do olhar. Talvez por essa razão os participantes surdos tenham apresentado durações de fixações mais longas nas legendas, mesmo elas sendo bem segmentadas. Esse é um aspecto que precisa ser analisado em pesquisas futuras, que observem as fixações individuais em palavras de conteúdo.

Segue o trecho de um relato de um participante ouvinte:

O8: Propaganda do Pedro Santos, presidente, candidato do PD, aí ele usou o tempo dele pra divulgar o plebiscito pela posse de terra, que era do começo de setembro, né, o tempo de votação, de 01 a 07 de setembro... no vídeo está várias imagens, né, de trabalhadores, de pessoas do povo mesmo... e é... apresentou uma logomarca, né, desse plebiscito, divulgando o plebiscito. A leitura desse foi mais fácil. Em vários momentos eu conseguia ver a imagem, 
né, ver o que tava acontecendo na imagem, mais que os outros. "Contra burguês, vote 4". (Informação verbal)

Os dados qualitativos na condição LBS sugerem que as legendas nessa condição podem ter facilitado a recepção de surdos e ouvintes, principalmente porque todos deram informações sobre o conteúdo do vídeo, bem como apresentaram detalhes, além de a maioria considerar que as legendas estavam em uma velocidade normal, o que pode ser um indicativo de conforto ${ }^{5}$ com elas.

Observamos que, sob a condição LMS, a maioria dos participantes comentou o conteúdo dos vídeos, tendo o último vídeo apresentado mais dificuldade para os surdos. Em todos os vídeos, somente um participante surdo apresentou detalhes, ao contrário do que ocorreu na condição LBS, na qual os surdos deram detalhes em todos os vídeos. Os ouvintes apresentaram recepção semelhante, pois, dentre os oito participantes ouvintes, quatro disseram que não puderam acompanhar imagem e legenda sem esforço. No caso dos surdos, foram cinco participantes.

Segue um trecho do relato de um participante surdo:

S5: Eu não consegui entender esse vídeo. Não consegui entender o contexto... tinham palavras que eu conhecia, mas outras pra mim eram desconhecidas, eu não consegui entender qual era o objetivo do vídeo, o que é que o rapaz estava falando... parece que ele está preocupado em incentivar o povo brasileiro a algo, mas qual é essa preocupação eu não entendi, qual é o objetivo, não ficou claro pra mim... eu consegui ler a legenda, tinha palavras que eu conhecia, mas elas pareciam não se conectar umas às outras, e aí eu não conseguia entender o objetivo geral. Outras palavras eu desconhecia completamente, nunca tinha visto, e aí eu acabei perdendo por completo o sentido do que estava sendo dito. Parece que por eu começar a não entender nada eu acho que talvez eu tenha perdido o interesse, e fiquei desatento, não entendi. As imagens também não pareciam ser nada interessantes, não estava nem interessado em olhar pras imagens pra ver se elas diziam algo. Parecia até, que, sei lá, que eram vários assuntos misturados, fala de saúde, fala de economia. (Informação verbal)

Em relação ao relato guiado, apenas três dos oito surdos pareceram equilibrar a atenção entre legenda e imagem. Um número maior de surdos do que de ouvintes mostrou fixações longas nas legendas pelas seguintes razões, segundo eles: frases "cortadas" (problemas de segmentação), que os faziam não querer sair da legenda; presença de palavras desconhecidas. Mais uma vez, surgiu o comentário sobre

5. Aqui denominamos conforto, no caso das legendas, o fato de o participante ter facilidade de processá-las. Nesse caso, ele é equivalente à boa recepção das legendas. O desconforto seria, portanto, a dificuldade de processar as legendas. No entanto, nem sempre esse conforto (ou desconforto) está relacionado às legendas. Muitas vezes, o desconforto é causado pelo excesso de imagens, pela presença de texto na imagem, repetindo o que está na legenda, pela presença de palavras desconhecidas, entre outros fatores. Ass vezes, o desconforto é grande ao ponto de interferir nos relatos sobre conteúdo e detalhes. Às vezes, não. Deixaremos isso claro ao longo do texto. 
legendas "cortadas", muito provavelmente relacionadas à má segmentação das legendas.

A maior parte dos surdos considerou as legendas como sendo rápidas ou muito rápidas. Já entre os ouvintes, metade as considerou rápidas. Esses dados reforçam a ideia de que a má segmentação das legendas pode influenciar na recepção dos participantes surdos e ouvintes. Conforme afirmamos anteriormente, faz-se importante investigar o fato de que a possível perturbação causada aos participantes pelas legendas mal segmentadas possa dar a falsa impressão de que elas são mais rápidas do que realmente são, quando na verdade estavam quebradas nos lugares errados, não obedecendo ao seu mais alto nível sintático (KARAMITROGLOU, 1998).

Os dados aqui apresentados sugerem, a princípio, que as legendas LMS podem ter sido mais desconfortáveis para surdos do que para ouvintes, principalmente pelo fato de os primeiros terem fornecido menos detalhes sobre o vídeo do que os últimos. Além disso, a maioria dos surdos considerou as legendas rápidas, mesmo sendo uma condição lenta, o que pode ser um indício de desconforto. Com relação às legendas LBS, as legendas LMS pareceram ser menos confortáveis para os dois grupos, pois na condição LBS todos os participantes conseguiram falar do conteúdo dos vídeos e dar mais detalhes do que na LMS.

Na condição RBS os surdos, de forma geral, relataram o conteúdo dos vídeos, sendo que, em cada um dos quatro vídeos, um surdo apresentou um maior número de detalhes do que os demais. Todos os ouvintes também comentaram acerca do conteúdo dos vídeos, destacando-se três ouvintes, que conseguiram apresentar detalhes. Tanto surdos quanto ouvintes pareceram ter tido mais conforto nessa condição do que na condição LMS. Do total de oito ouvintes, três disseram não ter conseguido acompanhar imagem e legenda sem esforço. Quanto aos surdos, dos oito, quatro disseram não ter conseguido.

Segue um trecho do relato de um participante ouvinte:

O1: O vídeo é do Paulo Martins e ele fala sobre... no começo fala sobre o desemprego e sobre uma siderúrgica que seria inaugurada aqui no Ceará, mas que não foi, as obras foram paradas e que prejudicou muita gente por conta do desemprego, ela ia dar empregos, mas não deu porque não foi instalada ainda. É... e mostra... dessa vez eu consegui prestar atenção no vídeo. Mostra a imagem da usina que seria instalada, mostra um campo todo verde... mostra também uma imagem de... uma manchete de jornal, e no final são as pessoas na rua. Eu acho que nesse vídeo eu consegui prestar atenção na legenda e no vídeo... porque o vídeo tem muita coisa que chama a atenção, esse campo que aparece... então pelas informações visuais que tem você consegue prestar atenção no vídeo, não só na legenda. (Informação verbal) 
Metade dos surdos (quatro) realizou uma leitura que parecia equilibrar mais a imagem e a legenda, enquanto apenas dois nesse grupo apresentaram fixações mais longas nas legendas. Nas gravações do olhar, também percebemos que os ouvintes fizeram menos fixações longas nas legendas. Metade dos participantes ouvintes pareceu fazer uma leitura equilibrando imagem e legenda, enquanto dois deles mostraram olhar praticamente só para a legenda.

Metade dos surdos considerou a velocidade da legenda normal, enquanto a outra metade a considerou muito rápida. A maioria dos ouvintes (seis) considerou que as legendas estavam entre rápidas e muito rápidas.

Os surdos reclamaram da presença de texto na imagem, que, segundo eles, os deixavam confusos. Reclamaram também da instabilidade do movimento na imagem, que para eles perturbou a leitura. Os surdos também mencionaram palavras desconhecidas e difíceis, afirmando que atrapalharam a leitura. Esses aspectos podem ter dificultado o processamento das legendas desses participantes. Dentre os oito ouvintes, apenas um mencionou a sua dificuldade com as "legendas quebradas", o que é curioso, pois se tratavam de legendas bem segmentadas, portanto não havia "quebras".

A condição RBS nos fez repensar se o parâmetro técnico de uma linha é realmente o ideal para esse gênero, pois mesmo as legendas estando em condição rápida, os relatos sobre o conteúdo não foram comprometidos e os desconfortos sugeridos pelos participantes estavam muito mais relacionados a excesso de imagens, presença de texto na imagem, palavras desconhecidas e densidade do conteúdo (que foi distribuído em várias legendas de uma linha). Assim, essa condição pode ter corroborado o estudo de De Bruycker e d'Ydewalle (2003), sobre a melhor recepção de legendas de duas linhas. No entanto, essa é uma questão que precisa ser melhor explorada em estudos futuros de rastreamento ocular em legendas.

Nos vídeos RMS, os dados qualitativos nos mostraram que ouvintes e surdos, mesmo apresentando poucos detalhes sobre o vídeo, conseguiram comentar acerca do seu conteúdo. Do total de ouvintes, quatro afirmaram não ter conseguido acompanhar imagem e legenda sem esforço. Quanto aos surdos, foram seis os que fizeram essa afirmação. Percebeu-se também um equilíbrio de surdos e ouvintes quanto ao possível tempo gasto na legenda - a maioria, nos dois grupos, pareceu ter feito mais fixações na legenda do que na imagem. No entanto, nessa condição, eles reclamaram mais da velocidade, mencionaram as legendas quebradas (mal segmentadas), sentiram mais desconforto em acompanhar as imagens do que nas outras condições bem segmentadas. Percebemos que nas duas condições mal 
segmentadas (LMS e RMS), os participantes reclamaram que as legendas estavam mais rápidas. Essa reclamação não apareceu nas condições bem segmentadas.

Segue o trecho do relato de um participante surdo:

S5: É o vídeo do candidato... tem um narrador, e as legendas vão falando sobre o candidato, aí aparecem umas imagens de vários locais no estado do Ceará, uma cidade do interior, perturbou um pouco por eu quis ficar olhando pra essas imagens, mas tentei focar nas legendas, falou sobre a Copa, o candidato disse que se eleito, ele iria trabalhar pra boa realização da Copa do Mundo aqui, em Fortaleza, todos os nossos direitos, direitos dos trabalhadores, direito a moradia... só. Ele apresenta as propostas dele pro estado do Ceará. Porque a legenda, eu achei muito difícil de entender, na verdade, então eu não entendi muito. Porque eu estava lendo a legenda e quando ela vai se tornando muito difícil, eu acabo perdendo a vontade de ler, aí fico olhando só mais nas imagens. (Informação verbal)

Surdos e ouvintes reclamaram da poluição visual, a qual perturbou a leitura das legendas. Reclamaram também da presença de "sentenças quebradas/ incompletas", mostrando que os problemas de segmentação presentes na legenda de fato chamaram sua atenção de forma negativa para a mesma.

Finalmente, percebemos que na condição RMS os surdos tiveram, a princípio, maior dificuldade com as legendas do que os ouvintes, pois entre os oito participantes surdos, 4 não comentaram sobre o conteúdo do vídeo.

\section{ANÁLISE EXPERIMENTAL}

O seguinte quadro representa os dados sobre o número de fixações realizadas pelos participantes ouvintes e surdos nas quatro condições experimentais: 
Quadro 3. Número de fixações de ouvintes e surdos na imagem e na legenda nas quatro condições

\begin{tabular}{|c|c|c|c|c|c|c|}
\hline $\begin{array}{c}\text { CONDI- } \\
\text { ÇÃOO }\end{array}$ & $\begin{array}{c}\text { PARTICI- } \\
\text { PANTE }\end{array}$ & $\begin{array}{c}\text { MÉDIA } \\
\\
\text { DO NÚ- } \\
\text { MERO } \\
\text { DE FIXA- } \\
\text { ÇÕES NA } \\
\text { IMAGEM }\end{array}$ & $\begin{array}{c}\text { MÉDIA } \\
\text { DO } \\
\text { NÚMERO } \\
\text { DE FIXA- } \\
\text { ÇÕES NA } \\
\text { LEGENDA }\end{array}$ & $\begin{array}{l}\text { PARTICI- } \\
\text { PANTE }\end{array}$ & $\begin{array}{c}\text { MÉDIA } \\
\text { DO } \\
\text { NÚME- } \\
\text { RO DE } \\
\text { FIXA- } \\
\text { ÇÔES NA } \\
\text { IMAGEM }\end{array}$ & $\begin{array}{c}\text { MÉDIA } \\
\text { DO } \\
\text { NÚME- } \\
\text { RO DE } \\
\text { FIXA- } \\
\text { ÇÕES NA } \\
\text { LEGEN- } \\
\text { DA }\end{array}$ \\
\hline LBS & \multirow{4}{*}{$\begin{array}{c}\text { OUVIN- } \\
\text { TE }\end{array}$} & 49,75 & 181,375 & \multirow{4}{*}{ SURDO } & 46,12 & 165,625 \\
\hline LMS & & 44,62 & 193,625 & & 46,62 & 165,75 \\
\hline RBS & & 50,37 & 185,375 & & 49,37 & 164,75 \\
\hline RMS & & 33,37 & 195,37 & & 34,37 & 175,50 \\
\hline
\end{tabular}

Os dados sobre o número de fixações, tanto na legenda quanto na imagem, sugerem que, no caso dos ouvintes, houve influência da má segmentação nas duas condições (LMS e RMS), diminuindo o número de fixações na imagem (LMS: 44,62/ RMS: 33,37) e aumentando o número de fixações na legenda (LMS: 193,625 /RMS: 195,37), em relação às outras condições. Quanto aos surdos, só foi possível visualizar essa influência na condição RMS, em que eles tiveram comportamento igual ao dos ouvintes, ou seja, diminuiu o número de fixações na imagem $(34,37)$ e aumentou nas legendas $(175,50)$, em relação às demais condições. Observamos também que, na condição RMS, o número de fixações na legenda foi o maior $(175,50)$ e o número de fixações na imagem $(34,37)$ foi o menor de todas as condições, mostrando que nessa condição os participantes fizeram mais idas à legenda. Acreditamos que esse número maior de visitas às legendas pode ter sido provocado pela má segmentação linguística, que pode ter exigido um maior esforço no processamento da leitura.

O seguinte quadro representa os dados sobre a duração das fixações realizadas pelos participantes ouvintes e surdos nas quatro condições do experimento: 
Quadro 4. Duração em milissegundos das fixações de ouvintes e surdos na imagem e na legenda nas quatro condições experimentais

\begin{tabular}{|c|c|c|c|c|c|c|}
\hline $\begin{array}{c}\text { CONDI- } \\
\text { ÇÃO }\end{array}$ & $\begin{array}{c}\text { PARTICI- } \\
\text { PANTE }\end{array}$ & $\begin{array}{c}\text { MÉDIA } \\
\text { DA DU- } \\
\text { RAÇÃO } \\
\text { DAS } \\
\text { FIXA- } \\
\text { ÇÕES NA } \\
\text { IMAGEM }\end{array}$ & $\begin{array}{c}\text { MÉDIA } \\
\text { DA DU- } \\
\text { RAÇÃO } \\
\text { DAS FIXA- } \\
\text { ÇÕES NA } \\
\text { LEGENDA }\end{array}$ & $\begin{array}{c}\text { PARTICI- } \\
\text { PANTE }\end{array}$ & $\begin{array}{c}\text { MÉDIA } \\
\text { DA DU- } \\
\text { RAÇÃO } \\
\text { DAS } \\
\text { FIXA- } \\
\text { ÇÕES NA } \\
\text { IMAGEM }\end{array}$ & $\begin{array}{c}\text { MÉDIA } \\
\text { DA DU- } \\
\text { RAÇÃO } \\
\text { DAS } \\
\text { FIXA- } \\
\text { ÇÕES NA } \\
\text { LEGEN- } \\
\text { DA }\end{array}$ \\
\hline LBS & & 298,75 & 266,25 & & 295 & 292,5 \\
\hline LMS & & 250 & 266,25 & & 290 & 291,2 \\
\hline RBS & & 275 & 256,25 & & 281,25 & 292,5 \\
\hline RMS & $\begin{array}{l}\text { OUVIN- } \\
\text { TE }\end{array}$ & 270 & 268,75 & & 291,25 & 302,5 \\
\hline
\end{tabular}

Os dados sobre a duração das fixações, tanto na legenda quanto na imagem, no caso dos ouvintes, sugerem que as condições LBS e LMS tiveram a mesma duração de fixações na legenda $(266,25 \mathrm{~ms})$, o que não nos proporciona indícios sobre a influência da segmentação na condição lenta nesse caso. Porém, em relação ao conforto, os dados revelam que a condição RBS foi a que teve a menor duração de fixações na legenda $(256,25 \mathrm{~ms})$ para o grupo de ouvintes, sugerindo, portanto, que foi a mais confortável de todas para esse grupo. Já a condição RMS foi a que apresentou a maior duração de fixações na legenda $(268,75 \mathrm{~ms})$, o que sugere um possível desconforto para os participantes ouvintes, embora a diferença entre a condição RMS e as condições LBS e LMS seja muito pequena (LBS e LMS 266,25 ; RBS - 268,75). Já no caso dos surdos, a velocidade não parece ter sido um entrave à sua recepção, em virtude de eles terem mantido um padrão de tempo de duração da fixação muito próximo nas condições LBS $(292,5 \mathrm{~ms})$, LMS $(291,2 \mathrm{~ms})$ e RBS (292,5ms), corroborando os resultados do Projeto MOLES (ARAÚJO; NASCIMENTO, 2011; ARAÚJO et al., 2012). Os dados também mostram que a duração das fixações dos surdos nas legendas na condição RMS (302,5ms) foi maior do que nas outras condições, sugerindo que essa foi a condição menos confortável para eles e indicando também que a má segmentação nas legendas rápidas pode ter dificultado a recepção desses participantes. Observa-se também que essa duração maior de fixações que ocorreu nas legendas RMS não foi percebida nas legendas 
LMS, o que sugere, a princípio, que não houve, necessariamente, um desconforto dos surdos na condição lenta mal segmentada. No entanto, esse dado não está totalmente claro, pois, na condição LMS, a duração das fixações na imagem foi menor, para surdos e ouvintes, em relação à condição LBS, o que poderia sinalizar uma interferência da má segmentação na recepção das legendas. Sobre isso, defendemos que um estudo estatístico mais apurado poderia levar a resultados mais precisos acerca da influência da segmentação na recepção das legendas mal segmentadas como um todo.

Outro resultado que não ficou claro, no que diz respeito aos participantes surdos, foi a duração das fixações na imagem e na legenda, na condição RBS: eles apresentaram uma duração de fixações maior na legenda $(292,5 \mathrm{~ms})$ do que na imagem (281,25ms), divergindo dos dados obtidos por Perego et al. (2010) sobre o ritmo normal de leitura de legendas. Observamos que a duração das fixações na legenda não foi maior na condição RBS em relação às demais condições - esperava-se essa duração maior, caso a velocidade tivesse interferido no conforto. Esse resultado nos fez questionar se o parâmetro de exibição das legendas em uma linha pode ter causado algum desconforto aos participantes, visto que, conforme d'Ydewalle e De Bruycker (2003), as legendas de duas linhas demonstram ser mais confortáveis, pois contêm mais informações verbais do que uma linha de legenda. Em relação a esse aspecto, necessitamos de mais pesquisas que discutam a relação da segmentação e do número de linhas de uma legenda.

Portanto, o que os dados nos mostraram é que as legendas RMS podem ter sido as mais desconfortáveis para surdos e ouvintes, pois para ambos os grupos a duração das fixações na legenda foi maior em relação às outras condições. Os dados também sugerem que, para os ouvintes, a condição RBS pode ter sido a mais confortável, pois a duração das fixações na legenda foi menor em relação às outras condições. No caso dos surdos, a duração das fixações foi maior na legenda do que na imagem, o que pode ser um indício de desconforto.

Quanto às condições LBS e LMS, no caso de ouvintes e surdos, embora as durações das fixações na legenda tenham sido iguais, os dados sugerem que pode ter havido mais conforto na condição LBS do que na LMS, pois na condição LMS a duração de fixações na imagem foi menor, o que pode ser indício da influência da má segmentação na recepção dos participantes.

Finalmente, podemos afirmar, no que diz respeito à duração das fixações na legenda para os ouvintes e, principalmente, para os surdos, que essa duração foi maior na condição RMS, o que pode sugerir que as condições LBS, LMS e RBS foram mais confortáveis. 
O Gráfico 1 traz o número de fixações de ouvintes e surdos em cada condição experimental.

GRÁFICO 1. Média do número de fixações de ouvintes e surdos na legenda

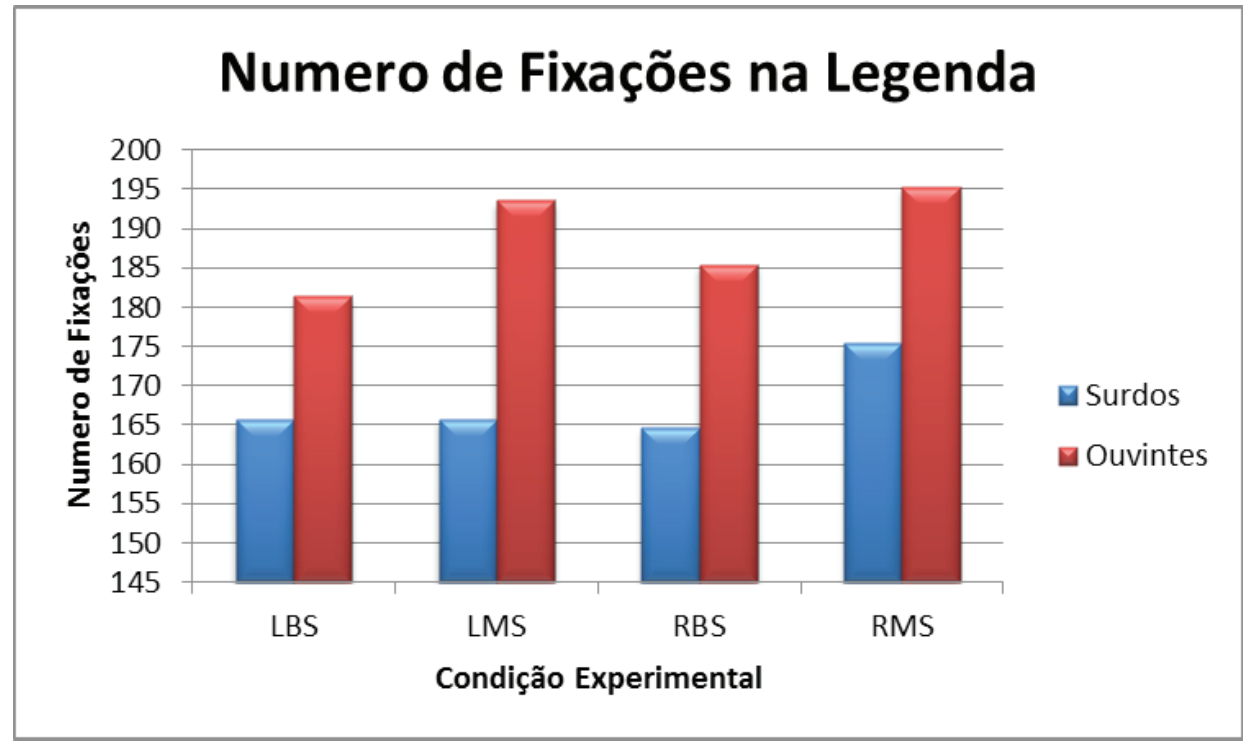

Fonte: Elaborado pela autora.

Podemos observar que, em termos gerais, o número de fixações na legenda foi maior no caso dos ouvintes do que no dos surdos, o que corrobora a ideia de Rayner et al. (2013) de que leitores mais hábeis fazem mais fixações no texto, só que mais curtas. Comparando as quatro condições (LBS, LMS, RBS, RMS), no caso dos surdos, vemos que o número de fixações foi maior na condição RMS, indicando que a má segmentação nas legendas rápidas pode ter influenciado negativamente a recepção dos participantes. Nas outras condições, o número foi praticamente o mesmo. No caso dos ouvintes, o número de fixações foi maior nas condições LMS e RMS, mostrando que a má segmentação pode ter influenciado no aumento de fixações dessas duas condições.

O Gráfico 2 apresenta a duração das fixações dos ouvintes nas legendas em cada condição experimental. 
GRÁFICO 2. Média das durações das fixações de ouvintes e surdos na legenda

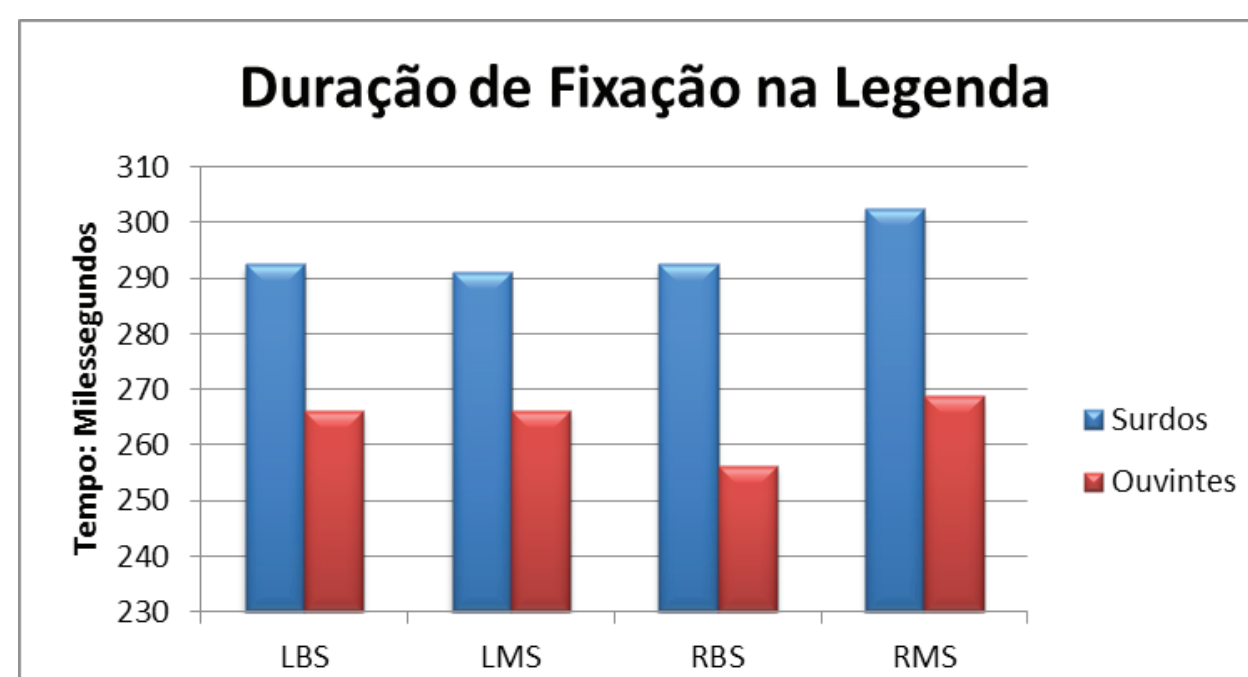

\section{Condição Experimental}

Fonte: Elaborado pela autora.

Em termos gerais, observamos que os ouvintes fizeram fixações mais curtas do que os surdos, corroborando mais uma vez os dados de Rayner et al. (2013). Em relação às quatro condições (LBS, LMS, RBS, RMS), no caso dos surdos, a maior duração das fixações foi nas legendas RMS, sugerindo que a sua recepção pode ter sido dificultada nessa condição. Nas outras três condições, a duração foi a mesma, não deixando claro onde pode ter havido maior ou menor problema de recepção.

Já os ouvintes apresentaram uma menor duração na condição RBS, o que sugere que a recepção pode ter sido facilitada nessa condição. A duração foi sutilmente maior na condição RMS, mostrando que a recepção pode ter sido um pouco mais dificultada nessa condição do que nas demais. As condições LBS e LMS apresentaram a mesma duração de fixações, não deixando muito claro onde poderia ter havido uma recepção mais facilitada ou dificultada.

Os dados até então apresentados ainda não são conclusivos, mas nos dão uma ideia de onde pode ter havido maior dificuldade de processamento das legendas por surdos e ouvintes. Adiante, apresentamos a triangulação dos dados resultantes das análises exploratória e experimental. 


\section{TRIANGULAÇÃO DOS DADOS: QUESTÕES DE PESQUISA E HIPÓTESES}

A fim de deixar mais clara a discussão sobre os resultados da análise, apresentamos a seguir as questões que regeram a pesquisa, as suas hipóteses e os comentários baseados nos dados fornecidos pelos protocolos (relatos e questionários) e pelo rastreador ocular.

Questão 1: Até que ponto legendas de campanhas políticas lentas bem segmentadas facilitam a recepção de surdos e ouvintes?

Hipótese: Legendas de campanhas políticas lentas bem segmentadas podem facilitar a recepção de surdos e ouvintes.

Os dados qualitativos gerados pelo estudo exploratório, relativos à recepção de surdos e ouvintes a legendas na condição LBS, sugerem que elas facilitaram a recepção dos dois grupos de participantes, principalmente porque todos deram informações sobre o conteúdo do vídeo, bem como apresentaram detalhes. Além disso, a maioria dos participantes considerou que as legendas estavam em uma velocidade normal, o que poderia ser um indicativo de conforto. Quanto aos dados numéricos gerados pelo estudo experimental, observamos que, na condição LBS, a análise feita vídeo a vídeo mostrou que essas legendas podem ter sido um pouco mais confortáveis para ouvintes do que para surdos. Já na análise geral, ouvintes e surdos demonstraram apresentar conforto nessa condição, pois os dois grupos fizeram fixações mais longas na imagem do que na legenda, o que sugere que a recepção das legendas foi facilitada. Desta forma, os dados qualitativos e quantitativos convergiram, corroborando a hipótese de que legendas de campanhas políticas lentas bem segmentadas facilitam a recepção de surdos e ouvintes.

Questão 2: Até que ponto legendas de campanhas políticas lentas mal segmentadas dificultam a recepção de surdos e ouvintes?

Hipótese: Legendas de campanhas políticas lentas mal segmentadas podem dificultar a recepção de surdos e ouvintes.

Os dados qualitativos relativos à recepção de surdos e ouvintes a legendas na condição LMS sugerem que elas foram mais confortáveis para ouvintes, principalmente porque conseguiram dar mais detalhes sobre o vídeo, do que para surdos. Além disso, a maioria dos surdos considerou as legendas rápidas, mesmo sendo em condição lenta, o que pode ser um indício de desconforto. No 
entanto, em comparação às legendas LBS, as legendas LMS pareceram ser menos confortáveis para os dois grupos de participantes, pois na condição LBS todos conseguiram comentar sobre o conteúdo dos vídeos e dar mais detalhes do que na condição LMS. No que diz respeito aos dados quantitativos, observamos que, na análise vídeo a vídeo, os dados sugerem que as legendas LMS apresentaram desconforto para surdos e ouvintes, sendo sutilmente maior no caso dos surdos. A análise geral mostrou que a duração das fixações, para surdos e ouvintes, foi maior na legenda do que na imagem, sugerindo desconforto dos dois grupos com essas legendas. Esses dados, portanto, vão ao encontro dos dados qualitativos para essa condição, corroborando a hipótese de que legendas de campanhas políticas lentas mal segmentadas dificultam a recepção de surdos e ouvintes.

Questão 3: Até que ponto legendas de campanhas políticas rápidas bem segmentadas facilitam a recepção de surdos e ouvintes?

Hipótese: Legendas de campanhas políticas rápidas bem segmentadas podem facilitar a recepção de surdos e ouvintes.

$\mathrm{Na}$ condição RBS, apesar de algumas reclamações sobre a velocidade da legenda, os participantes surdos e ouvintes reportaram as informações presentes nos vídeos, tendo um número maior de surdos do que de ouvintes apresentado mais detalhes sobre o conteúdo. No entanto, as reclamações sobre desconforto com a imagem e as palavras desconhecidas foram maiores por parte dos surdos do que dos ouvintes. Nesta condição, atentamos para o fato de que legendas de uma linha no gênero campanha política possam causar certo desconforto aos espectadores. No que diz respeito ao estudo experimental, observamos que, na análise vídeo a vídeo, os dados ficaram equilibrados, não deixando muito clara a questão do possível conforto/desconforto para os dois grupos de participantes. Já os dados gerais deram indícios de que houve possivelmente um maior conforto com essas legendas por parte dos ouvintes, já que a duração das fixações desses participantes foi maior na imagem do que na legenda. Já os surdos apresentaram a duração maior na legenda do que na imagem, o que sugere que esse grupo de participantes pode ter tido maior desconforto. Esses dados corroboram os do estudo exploratório, que mostrou que os surdos apresentaram mais reclamações do que os ouvintes. Desta forma, a hipótese de que legendas de campanhas políticas rápidas bem segmentadas facilitam a recepção de surdos e ouvintes foi corroborada para os ouvintes. No caso dos surdos, a hipótese foi parcialmente confirmada, já que os dados exploratórios 
mostraram que a recepção foi facilitada, mas os dados experimentais sugeriram desconforto.

Questão 4: Até que ponto legendas de campanhas políticas rápidas mal segmentadas dificultam a recepção de surdos e ouvintes?

Hipótese: Legendas de campanhas políticas rápidas mal segmentadas podem dificultar a recepção de surdos e ouvintes.

Os dados do estudo exploratório mostram que, dentre os oito participantes surdos, quatro não conseguiram falar sobre o conteúdo do vídeo, o que não ocorreu com os ouvintes, sugerindo que os surdos tiveram mais dificuldade com essas legendas. Mesmo assim, os ouvintes apresentaram menos detalhes do que em outras condições. Houve muitas reclamações por parte dos dois grupos sobre a velocidade das legendas e sobre a presença de frases "quebradas" (reclamação dos participantes que relacionamos a problemas de segmentação), o que sugere que a recepção de ambos os grupos foi dificultada. No estudo experimental, observamos que, na análise vídeo a vídeo, os ouvintes apresentaram uma recepção um pouco melhor do que os surdos. Com relação aos dados numéricos gerais, a duração das fixações, no caso dos ouvintes, foi maior na imagem do que na legenda, o que sugere que não houve desconforto. Já os surdos apresentaram a duração maior na legenda do que na imagem, o que sugere que esse grupo de participantes pode ter tido maior desconforto com essas legendas do que os ouvintes. No entanto, o estudo exploratório deixa claro que, mesmo tendo uma recepção melhor do que a dos surdos, os ouvintes também demonstraram muito desconforto com as legendas RMS. Desta forma, o resultado da pesquisa corrobora, no caso dos surdos, a hipótese de que legendas de campanhas políticas rápidas mal segmentadas dificultam a recepção. No caso dos ouvintes, a hipótese foi parcialmente confirmada, já que os dados exploratórios mostraram que a recepção foi dificultada, mas os dados experimentais sugeriram possível conforto.

Apesar de algumas pequenas divergências entre dados qualitativos e quantitativos, os resultados sugerem que a segmentação é um parâmetro relevante na legendagem e que pode, sim, influenciar a recepção de surdos e ouvintes quanto a legendas do gênero campanha política. No que diz respeito à velocidade da legenda, os dados nos dão indícios de que esse elemento não foi um entrave à recepção de legendas, visto que os relatos dos participantes só apresentavam perda de conteúdo quando eles assistiram a legendas rápidas mal segmentadas, o que acreditamos ter sido influência da má segmentação, e não da velocidade. 


\section{CONSIDERAÇÕES FINAIS}

A pesquisa aqui descrita teve como principal objetivo analisar a recepção de surdos e ouvintes da cidade de Fortaleza à LSE de programas políticos na televisão, tendo como principal foco os parâmetros da segmentação e da velocidade.

Sabemos que uma pesquisa sempre pode ser continuada ou modificada e temos consciência de que o tema tratado nesta pesquisa está longe de ser esgotado. Por isso, sugerimos que novas pesquisas sejam desenvolvidas, analisando outros gêneros e utilizando dados estatísticos que possam nos dar respostas mais claras sobre a análise experimental. Uma perspectiva para esta pesquisa seria a de analisar mais a fundo a questão da influência de legendas de uma linha na recepção de legendas de campanhas políticas. Além disso, defendemos a ideia de que novas pesquisas baseadas na triangulação de dados experimentais e exploratórios possam preencher as várias lacunas existentes no que diz respeito à recepção de legendas, principalmente da comunidade surda.

Acreditamos que as reflexões levantadas a partir desta pesquisa são promissoras, no sentido de que podem fomentar os estudos referentes à Tradução Audiovisual Acessível e à legendagem, mais especificamente a LSE. Em um sentido mais amplo, a pesquisa visa contribuir com a área da Linguística Aplicada. Acreditamos ainda na importância de futuros investimentos em pesquisas que utilizem o rastreamento ocular para a investigação acerca da recepção de surdos e ouvintes quanto a diferentes tipos de legendas e gêneros, como forma de melhorar a sua acessibilidade aos meios audiovisuais. Finalmente, acreditamos que pesquisas como esta possam contribuir com a formação de futuros legendistas, tornando-os conscientes da importância da segmentação linguística para a qualidade das legendas que são produzidas para todos os tipos de público.

\section{REFERÊNCIAS BIBLIOGRÁFICAS}

ADERALDO, M. F. Proposta de parâmetros descritivos para audiodescrição à luz da interface revisitada entre tradução audiovisual acessivel e semiótica social - multimodalidade. 206f. Tese (Doutorado) - Faculdade de Letras Estrangeiras, Programa de Pós-Graduação em Estudos Linguísticos, Universidade Federal de Minas Gerais, Belo Horizonte - MG, 2014.

ARAÚJO, V. L. S.; FRANCO, E. (2003). Reading television: checking deaf people's reactions to closed subtitling in Fortaleza, Brazil. The Translator. v. 9, n. 2, pp. 249267. 
ARAúJO, V. L. S. (2004). Closed subtitling in Brazil. Topics in audiovisual translation. Amsterdam: John Benjamins Publishing Company. v. 1, pp. 199-212.

ARAÚJO, V. L. S. (2005). A legendagem para surdos no Brasil. Questões de Linguística Aplicada: miscelânea. Fortaleza: EdUECE. pp. 163-188.

ARAÚJO, V. L. S. (2007). Subtitling for the deaf and hard-of-hearing in Brazil. Media for All: subtitling for the deaf, audio description and sign language. Nova Jersey, EUA: Rodopi. v. 30, pp. 99-107.

ARAÚUJO, V. L. S. (2008). Por um modelo de legendagem para Brasil. Tradução e Comunicação. Revista Brasileira de Tradutores, São Paulo: UNBERO, n. 17, pp. 59-76.

ARAÚJO, V. L. S. (2009). In Search of SDH Parameters for Brazilian Party Political Broadcasts. The Sign Language Translator and Interpreter, Manchester: St. Jerome Publishing Company, v. 3, n. 2, pp. 157-167.

ARAúJO, V. L. S.; MONTEIRO, S. M. M.; VIEIRA, P. A. (2013). Legendagem para surdos e ensurdecidos (LSE): um estudo de recepção com surdos da região Sudeste. TRADTERM, v. 22, pp. 273-292. Disponível em: <http://www.revistas.usp.br/ tradterm/article/view/69132>. Acesso em: 10 maio 2014.

ARAÚJO, V. L. S.; CHAVES, E. G. (2012). Etiquetas de segmentação: uma proposta para análise da segmentação em legendas intralinguísticas de filmes brasileiros. In: Anais do XI Encontro de Linguística de Corpus (ELC). Disponível em: <http://www.nilc.icmc.usp. br/elc-ebralc2012/anais/completos/103954.pdf>. Acesso em: 10 jan. 2014.

ARAÚJO, V. L. S.; NASCIMENTO, A. K. P. (2011). Investigando parâmetros de legendas para surdos e ensurdecidos no Brasil. In: FROTA, M. P.; MARTINS, M. A. P. (Org.). Tradução em Revista, v. 2, pp. 1-18. Disponível em: < http://www.maxwell.lambda.ele. puc-rio.br/18862/18862>. Acesso em: 3 mar. 2014.

ASSIS, I. A. P. A segmentação na LSE de Amor Eterno Amor: uma análise baseada em corpus. 2015 (Bacharelado em Letras Inglês). 71 f. Universidade Estadual do Ceará, FortalezaCE, 2013.

CASTILHO, A. de. Nova gramática do português brasileiro. São Paulo: Contexto, 2012.

CHAVES, E. G. (2012). Legendagem para surdos e ensurdecidos: um estudo baseado em corpus da segmentação nas legendas de filmes brasileiros em DVD. Dissertação de Mestrado - Programa em PósGraduação em Linguística Aplicada, Universidade Estadual do Ceará, Fortaleza-CE. 
DE BRUYCKER, W; D'YDEWALLE, G. Reading native and foreign language television subtitles in children and adults. In: HYONA, J.; RADACH, R.; DEUBEL, H. (Org.). The mind's eye: cognitive and applied aspects of eye movements. Oxford, UK: Research Lirias, 2003. p. 671-684.

DE LINDE, Z.; KAY, N. The semiotics of subtitling. Manchester: St. Jerome Publishing, 1999.

D'YDEWALLE, G.; RENSBERGEN, J.; POLLET, J. Reading a message when the same message is available auditorily in another language: the case of subtitling. In: O'Regan, J. K.; LÉVY-SCHOEN, A. (Org.). Eye movements: from physiology to cognition. Amsterdam and New York: Elsevier Science Publishers, 1987. p. 313-321.

DÍAZ CINTAS, J.; REMAEL, A. Audiovisual translation: subtitling. Manchester: St. Jerome Publishing Company, 2007.

DINIZ, N. S. L. A segmentação em legendagem para surdos e ensurdecidos: um estudo baseado em corpus. 149f. Dissertação (Mestrado) - Programa de Pós-Graduação em Estudos Linguísticos, Universidade Federal de Minas Gerais, Belo Horizonte - MG, 2012.

IVARSSON, J.; CARROLL, M. Subtitling. Simrishamm, Suécia: TransEditHB, 1998.

KARAMITROGLOU, F. (1998). A proposed set of subtitling standards in Europe. Translation Journal, v. 2, n. 2, p. 1-15. Disponível em: < http://translationjournal.net/ journal//04stndrd.htm >. Acesso em: 8 mar. 2014.

NAVES, S. B.; MAUCH, C.; ALVES, S. F.; ARAÚJO, V. L. S. A. Guia para Produções Audiovisuais Acessíveis, Secretaria do Audiovisual, Ministério da Cultura, 2016.

PAVAKANUN, U. Incidental acquisition of foreign language tbrough subtitled television programs as a function of similarity with native language and as a function of presentation mode. Unpublished doctoral thesis, Leuven, Belgium, University of Leuven, 1992.

PEREGO, E. What would we read best? Hypotheses and suggestions for the location of line breaks in film subtitles. In: The Sign Language Translator and Interpreter. Manchester, UK: St. Jerome Publishing, 2008. p. 35-63.

PEREGO, E.; DEL MISSIER, F. PORTA, M.; MOSCONI, M. The cognitive effectiveness of subtitle processing. In: Media Psychology. Philadelphia, PA: Routledge, p. 243-272, 2010. Disponível em: <http://www2.units.it/delmisfa/papers/ SubtitlesProcessing2010.pdf $>$. Acesso em: 21 maio 2014. 
RAYNER, K.; POLLATSEK, A. The psychology of reading. Englewood Cliffs, NJ: Prentice Hall, 1989.

REID, H. Literature on the screen: subtitle translation for public broadcasting. In: BART, W.; D'HAEN, T. (Org.). Sometbing understood: studies in Anglo-Dutch literary translation. Amsterdam: Rodopi, 1990. p. 97-107.

REICHLE, E. D.; RAYNER, K; POLLATSEK, A. The E-Z reader model of eye-movement control in reading: comparisons to other models. Bebavioral and Brain Sciences, v. 26, Cambridge University Press, p. 445-526, 2003.

ROMERO-FRESCO, P. Standing on quicksand: hearing viewers' comprehension and reading patterns of respoken subtitles for the news. In DÍAZ CINTAS, J.; MATAMALA, A.; NEVES, J. (Org.). New insights into audiovisual translation and accessibility: Media for All 2. Amsterdã: Rodopi, 2010. p. 175-195.

STAUB, A.; RAYNER, K. Eye movements and on-line comprehension processes. In: GASKELL, M. G. (Ed.). The Oxford Handbook of Psycholinguistics. Oxford: Oxford University Press, 2007. p. 327-343. Disponível em: <http://people.umass.edu/ astaub/StaubRayner2007_proof.pdf $>$. Acesso em: 7 jan. 2016.

SZARKOWSKA, A.; KREJTZ, I.; KREJTZ, K.; DUCHOWSKY, A. Harnessing the potential of eye tracking for media accessibility. In: GRUCZA, Sambor; PŁUŻYCZKA, Monika; ZAJĄC, Justyna (Ed.). Translation Studies and Eye-Tracking Analysis. Frankfurt am Mein: Peter Lang, 2013. p. 153-83.

Recebido: 19/05/2017

Aceito: 01/08/2017 